\title{
ANÁLISE ANTROPOMÉTRICA DOS TRABALHADORES NA PRODUÇÃO DE FERRAMENTAS
}

\footnotetext{
Pompeu Paes Guimarães ${ }^{1}$, Nilton César Fiedler ${ }^{2}$, Flavio Cipriano de Assis do Carmo $^{3}$, Saulo Boldrini Gonçalves ${ }^{3}$, Daniel Pena Pereira ${ }^{4}$

${ }^{1}$ Professor da Universidade Federal Rural do Semi-Árido, Mossoró, Rio Grande do Norte, Brasil. e-mail: pompeu.guimaraes@ufersa.edu.br

${ }^{2}$ Professor da Universidade Federal do Espírito Santo, Jerônimo Monteiro, Espírito Santo, Brasil

${ }^{3}$ Doutorando, Programa de Pós-graduação em Ciências Florestais da Universidade Federal do Espírito Santo, Jerônimo Monteiro, Espírito Santo, Brasil

${ }^{4}$ Professor da Universidade Federal do Triângulo Mineiro, Uberaba, Minas Gerais, Brasil

Recebido em: 03/10/2016 - Aprovado em: 21/11/2016 - Publicado em: 05/12/2016 DOI: 10.18677/EnciBio_2016B_148

Esta pesquisa objetivou avaliar ergonomicamente os postos de trabalho de uma fábrica de produção de ferramentas pelo processo de forjamento por martelamento, abrangendo a antropometria dos trabalhadores e seu posto de trabalho. As superfícies horizontais de trabalho apresentam dimensões maiores que 0 alcance máximo de trabalho $\left(1,0 \mathrm{~m}^{2}\right)$. A altura da bancada de trabalho ideal seria de $0,9 \mathrm{~m}$, no entanto, a maioria das atividades apresentou bancadas mais baixas que 0 recomendado. Em relação aos pedais, todas as máquinas possuem altura dentro do tolerado $(0,2 \mathrm{~m})$, exceto a forjadora 2, com dimensões menores e devem ser redimensionadas. Em contrapartida, as áreas dos pedais foram inferiores a 0,03 $\mathrm{m}^{2}$. Com base nas medidas antropométricas analisadas é preciso readequar as superfícies de trabalho e bancadas das máquinas às alturas corretas de trabalho e área de alcance máximo dos trabalhadores para um melhor conforto, segurança e bem estar dos trabalhadores.
}

PALAVRAS-CHAVE: Antropometria, ergonomia e produção de ferramentas.

\section{ANTHROPOMETRIC ANALYSIS OF WORKERS IN TOOLS PRODUTION}

\begin{abstract}
This research evaluates the ergonomically jobs of a tool for forging process production plant by pounding, covering the anthropometry of workers and their jobs. The horizontal work surfaces are larger in size than the maximum working range (1.0 $\mathrm{m}^{2}$ ). The ideal height of the workbench would be $0.9 \mathrm{~m}$, however, most of the stands had lower activities than recommended. In relation to the pedals, all the machines have height within the tolerated $(0.2 \mathrm{~m})$, forger 2 except with smaller and must be resized dimensions. In contrast, areas of the pedals were less than $0.03 \mathrm{~m}^{2}$. Based on anthropometric measurements analyzed it takes readjust work surfaces and countertops machines to correct working heights and area of maximum range of workers.
\end{abstract}

KEYWORDS: Anthropometry, ergonomics and tool production. 


\section{INTRODUÇÃO}

O dimensionamento de equipamento, ferramentas, máquinas e postos de trabalho pode ser subsidiado por levantamentos antropométricos de determinada população, e ainda, verificar a adequação dos mesmos às características dos trabalhadores, sem causar danos à saúde e desconforto ao trabalhador (SILVA et al., 2006).

Em avaliações no setor florestal, GUIMARÃES et al. (2016) avaliaram as condições antropométricas dos trabalhadores e correlacionaram com as potencialidades e imperfeições de marcenarias do sul do Espírito Santo. FERNANDES et al. (2011) avaliaram ergonomicamente a cabine do Feller Buncher levando em consideração a avaliação antropométrica dos operadores com mediadas em pé e sentado. LOPES et al. (2013) avaliaram a antropometria de trabalhadores da implantação florestal. A antropometria também deve ser levada em consideração no planejamento das atividades de produção de ferramentas florestais.

O processo de produção de ferramentas se faz pelo processo de forjamento por martelamento, por meio de operações mecânicas com golpes rápidos aplicam pressão ao metal aquecido no momento do contato do martelo da forjadora com a peça metálica (GUIMARAES et al., 2013).

Durante a jornada de trabalho na fábrica de produção de ferramentas no processo de forjamento por martelamento, a postura básica de trabalho é de pé, onde $\mathrm{o}$ acionamento da máquina acontece com os membros inferiores e com as mãos, por controle mecânico, o que exige grande precisão no trabalho (GUIMARAES, 2011). Assim, os funcionários ficam acometidos a trabalhos estáticos, exigindo contração contínua de alguns músculos para manter a posição de trabalho (IIDA, 2005). Permanecer nesta postura pode prejudicar a circulação sanguínea nos vasos capilares e provocar dores.

Traçar a caracterização do perfil antropométrico dá sustentação para compreender constituição física dos trabalhadores atuantes na cadeia produtiva florestal, sendo ferramenta importante para satisfazer ergonomicamente o posto de trabalho de forma que se harmonize ao trabalhador (GUIMARAES et al., 2014).

Desta forma, objetivou-se por meio desta pesquisa traçar o perfil antropométrico dos trabalhadores, compará-lo com as dimensões dos postos de trabalho do processo de produção de ferramentas.

\section{MATERIAL E MÉTODOS}

A região de estudo se encontra no galpão de produção de uma empresa produtora de ferramentas, no município de Marechal Floriano, distrito de Araguaia, no Espírito Santo.

A jornada de trabalho ocorria de segunda a sexta feira, com entrada acontecendo às $7 \mathrm{~h}$, pausa para almoço de 11 às $12 \mathrm{~h}$ e $15 \mathrm{~min}$ e finaliza às $17 \mathrm{~h}$. $\mathrm{O}$ Quadro 1 descreve os postos de trabalho durante o processo de produção das ferramentas (Quadro 1). 
QUADRO 1 - Descrição do processo de produção de ferramentas

\begin{tabular}{|c|c|c|}
\hline $\begin{array}{l}\text { Sequencia de } \\
\text { produção }\end{array}$ & Atividade & Descrição \\
\hline 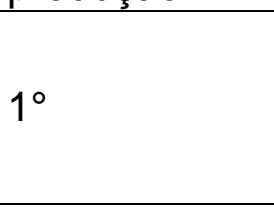 & Corte 1 & $\begin{array}{l}\text { Operação em que se mede e secciona a barra } \\
\text { de aço, com o uso da máquina de corte, servindo } \\
\text { para reduzir a barra de ferro em seu } \\
\text { comprimento. }\end{array}$ \\
\hline $2^{\circ}$ & Corte 2 & $\begin{array}{l}\text { Operação em que se mede e secciona a barra } \\
\text { de aço, com o uso da máquina de corte, servindo } \\
\text { para reduzir a barra de ferro em sua largura. }\end{array}$ \\
\hline $3^{\circ}$ & Orvado & $\begin{array}{l}\text { Máquina que molda a extremidade da barra de } \\
\text { aço em formato cilindro para o encaixe do cabo } \\
\text { da ferramenta. }\end{array}$ \\
\hline $4^{\circ}$ & Soldagem & $\begin{array}{l}\text { União de peça cilíndrica com a superfície de } \\
\text { corte da ferramenta. }\end{array}$ \\
\hline $5^{\circ}$ & Viragem & $\begin{array}{l}\text { Promove a angulação de superfícies que será o } \\
\text { local de corte da ferramenta. }\end{array}$ \\
\hline $6^{\circ}$ & Forjadora 1 & $\begin{array}{l}\text { Aplicação de pressão utiliza para alongar as } \\
\text { dimensões da barra de aço em seu } \\
\text { comprimento. }\end{array}$ \\
\hline $7^{\circ}$ & Forjadora 2 & $\begin{array}{l}\text { Aplicação de pressão utiliza para acabamento da } \\
\text { superfície. }\end{array}$ \\
\hline $8^{\circ}$ & Têmpera & $\begin{array}{l}\text { Aquecimento das ferramentas em fornos e } \\
\text { resfriamento a óleo para promover durabilidade e } \\
\text { resistência. }\end{array}$ \\
\hline $9^{\circ}$ & Esmeril & Afiação das lâminas das ferramentas \\
\hline $10^{\circ}$ & $\begin{array}{l}\text { Inserção de } \\
\text { cabos }\end{array}$ & $\begin{array}{l}\text { Fase em que se insere o cabo das ferramentas à } \\
\text { superfície de corte. }\end{array}$ \\
\hline $11^{\circ}$ & Envernizamento & $\begin{array}{l}\text { Local onde se promove o acabamento com } \\
\text { pintura e fixação do logotipo da empresa lâmina } \\
\text { de corte. }\end{array}$ \\
\hline
\end{tabular}

As ferramentas são produzidas utilizando como matéria prima barra de aço carbono, sendo produzidos ao todo 39 modelos diferentes de ferramentas como facas, chibanca, picaretam cutelo, foice, podão, cavadeira, enxada, enxó, machado, machadinha, lâminas para roçadeira.

Os dados antropométricos e de condições de trabalho foram coletados no período de maio a junho de 2010. Com uma trena foram mensuradas nas máquinas: altura e dimensões das bancadas e dos mecanismos de acionamento. $O$ perfil antropométrico dos trabalhadores foi tomado por meio de medidas estáticas e dinâmicas do operador com o uso de fitas métricas, balança e formulários (Quadro 2). 
QUADRO 2 - Descrição das medidas antropométricas avaliadas.

\begin{tabular}{|c|c|}
\hline Medidas & Descrição \\
\hline 1. Estatura & Distância vertical do topo da cabeça ao solo \\
\hline 2. Altura do nível dos olhos & $\begin{array}{l}\text { Distância vertical entre o solo até o nível dos olhos na } \\
\text { inserção da pálpebra superior e inferior }\end{array}$ \\
\hline 3. Altura do ouvido & Distância vertical entre o solo e a parte superior da orelha \\
\hline 4. Altura do punho & $\begin{array}{l}\text { Distância vertical entre o solo até punho com os braços } \\
\text { paralelos ao corpo }\end{array}$ \\
\hline 5. Altura do joelho na rótula & Distância vertical da parte central do joelho e o solo \\
\hline 6. Altura da espinha ilíaca & Distância vertical entre a espinha ilíaca e o solo \\
\hline 7. Altura do tórax & Distância vertical entre o tórax e o solo \\
\hline 8. Altura do umbigo & Distância vertical do umbigo ao solo \\
\hline 9. Altura do mento & Distância vertical entre o mento (queixo) e o solo \\
\hline 10. Altura do ombro & Distância vertical do ombro, no acômio, até o solo \\
\hline 11. Altura do cotovelo & $\begin{array}{l}\text { Distância vertical da extremidade do cotovelo com o } \\
\text { antebraço dobrado ( } 909 \text { ) }\end{array}$ \\
\hline 12. Altura entrepernas & Distância vertical entre a virilha e o solo \\
\hline 13. Comprimento do braço & $\begin{array}{l}\text { Comprimento do braço, entre os ombros, no acrômio e } \\
\text { cotovelo, em pega empunhadura ( } 909 \text {. Obtido pela } \\
\text { diferença entre a altura dos ombros e altura do cotovelo }\end{array}$ \\
\hline $\begin{array}{l}\text { 14. Alcance inferior máximo } \\
\text { até a extremidade do } \\
\text { dedo médio }\end{array}$ & $\begin{array}{l}\text { Distância vertical entre o solo e o dedo médio com os } \\
\text { braços paralelos ao corpo }\end{array}$ \\
\hline $\begin{array}{l}\text { 15. Alcance frontal da mão em } \\
\text { pega empunhadura }\end{array}$ & $\begin{array}{l}\text { Comprimento do antebraço e mão fechada indicando o } \\
\text { alcance de comandos }\end{array}$ \\
\hline $\begin{array}{l}\text { 16. Alcance frontal do } \\
\text { antebraço até a } \\
\text { extremidade do dedo } \\
\text { médio }\end{array}$ & $\begin{array}{l}\text { Comprimento do antebraço, entre o cotovelo e a } \\
\text { extremidade do dedo médio. Obtido pela diferença entre o } \\
\text { comprimento do membro superior e o comprimento do } \\
\text { braço }\end{array}$ \\
\hline $\begin{array}{l}\text { 17. Largura da mão no } \\
\text { polegar }\end{array}$ & $\begin{array}{l}\text { Largura da mão aberta medida do dedo polegar ao dedo } \\
\text { mínimo }\end{array}$ \\
\hline 18. Largura da mão fechada & $\begin{array}{l}\text { Largura da mão fechada medida do dedo polegar ao dedo } \\
\text { mínimo }\end{array}$ \\
\hline $\begin{array}{l}\text { 19. Comprimento da mão até } \\
\text { a extremidade do dedo } \\
\text { médio }\end{array}$ & Comprimento da palma da mão, com a mão aberta \\
\hline
\end{tabular}

Os dados antropométricos foram analisados por estatística descritiva como média, desvio padrão e coeficiente de variação e por intermédio do cálculo de percentis, que divide a distribuição da frequência ordenada em 100 partes iguais. Com as medidas antropométricas foi possível dimensionar algumas variáveis e EPIs do processo de produção de ferramentas.

As variáveis antropométricas foram classificadas quanto ao coeficiente de variação da distribuição:

- Inferior a $10 \%$, houve pouca variabilidade entre a distribuição ou todos os valores estavam muito próximos da média, neste caso, considerou-se a distribuição homogênea;

- Se o coeficiente de variação situou-se entre 10 e $30 \%$ existia uma distribuição média entre as variáveis;

- Se o coeficiente de variação fosse maior que 30\%, apresentou uma grande variabilidade e os dados se distribuem heterogeneamente. 


\section{RESULTADOS E DISCUSSÃO}

A importância da obtenção de dados e a construção de tabelas antropométricas para os trabalhadores são decorrentes da grande variação da população brasileira, de diferentes etnias e características físicas variáveis (LOPES et al., 2013). Ao todo foram avaliados 35 funcionários do total de 40 na produção de ferramentas, com as medidas antropométricas e sua dispersão (Tabela 1).

TABELA 1. Medidas antropométricas dos trabalhadores.

\begin{tabular}{|c|c|c|c|c|c|c|c|}
\hline & \multicolumn{3}{|c|}{ Percentis } & \multirow[t]{2}{*}{$\bar{x}$} & \multirow{2}{*}{$\begin{array}{l}\text { Desv } \\
\text { Pad }\end{array}$} & \multirow{2}{*}{$\begin{array}{l}\text { CV } \\
(\%)\end{array}$} & \multirow{2}{*}{ Distr. } \\
\hline & $5 \%$ & $50 \%$ & $95 \%$ & & & & \\
\hline 1. Idade (anos) & $\begin{array}{l}19 \\
7\end{array}$ & 33,0 & 42,2 & $\begin{array}{l}30 \\
7\end{array}$ & 7,7 & 25,0 & Heter. \\
\hline 2. Peso $(\mathrm{kg})$ & $\begin{array}{l}61 \\
4\end{array}$ & 75,0 & 96,0 & $\begin{array}{l}75 \\
3\end{array}$ & 11,3 & 15,1 & Média \\
\hline 3. Estatura (m) & 1,7 & 1,8 & 1,9 & 1,8 & 5,7 & 3,2 & Homog. \\
\hline 4. $I M C^{*}$ & $\begin{array}{l}19 \\
6\end{array}$ & 23,9 & 30,6 & $\begin{array}{l}24, \\
0\end{array}$ & 3,62 & 15,1 & Média \\
\hline 5. Altura do nível do olho (m) & 1,6 & 1,7 & 1,7 & 1,7 & 5,7 & 3,4 & Homog. \\
\hline 6. Altura do ouvido (m) & 1,5 & 1,6 & 1,7 & 1,6 & 5,8 & 3,6 & Homog. \\
\hline 7. Altura do punho (m) & 0,8 & 0,8 & 0,9 & 0,8 & 4,8 & 5,7 & Homog. \\
\hline 8. Altura do joelho na rótula $(\mathrm{m})$ & 0,4 & 0,5 & 0,5 & 0,5 & 3,8 & 7,8 & Homog. \\
\hline 9. Altura do tórax (m) & 1,2 & 1,3 & 1,4 & 1,3 & 6,3 & 4,9 & Homog. \\
\hline 10. Altura do umbigo (m) & 1,0 & 1,1 & 1,2 & 1,1 & 5,8 & 5,4 & Homog. \\
\hline 11. Altura do mento $(\mathrm{m})$ & 1,5 & 1,6 & 1,6 & 1,5 & 6,0 & 3,9 & Homog. \\
\hline 12. Altura do ombro (m) & 1,4 & 1,4 & 1,5 & 1,4 & 6,2 & 4,3 & Homog. \\
\hline 13. Altura do cotovelo (m) & 1,0 & 1,1 & 1,2 & 1,1 & 17,5 & 16,3 & Média \\
\hline 14. Altura entrepernas (m) & 0,7 & 0,8 & 0,8 & 0,8 & 5,1 & 6,6 & Homog. \\
\hline $\begin{array}{l}\text { 15. Alcance inferior máximo até a } \\
\text { extremidade do dedo médio }(\mathrm{m})\end{array}$ & 0,6 & 0,7 & 0,7 & 0,7 & 3,4 & 5,2 & Homog. \\
\hline $\begin{array}{l}\text { 16. Alcance frontal da mão em pega } \\
\text { empunhadura }(\mathrm{m})\end{array}$ & 0,4 & 0,4 & 0,4 & 0,4 & 2,1 & 5,3 & Homog. \\
\hline $\begin{array}{l}\text { 17. Alcance frontal do antibraço até a } \\
\text { extremidade do dedo médio }(\mathrm{m})\end{array}$ & 0,4 & 0,5 & 0,5 & 0,5 & 2,6 & 5,4 & Homog. \\
\hline 18. Largura da mão no polegar (m) & 0,2 & 0,2 & 0,2 & 0,2 & 1,8 & 8,6 & Homog. \\
\hline 19. Largura da mão fechada $(\mathrm{m})$ & 0,1 & 0,1 & 0,1 & 0,1 & 0,9 & 8,0 & Homog. \\
\hline $\begin{array}{l}\text { 20. Comprimento da mão na extremidade } \\
\text { do dedo médio }(\mathrm{m})\end{array}$ & 0,2 & 0,2 & 0,2 & 0,2 & 1,0 & 5,2 & Homog. \\
\hline $\begin{array}{l}\text { 21. Comprimento do braço, antebraço e } \\
\text { mãos até a extremidade do dedo } \\
\text { médio }(\mathrm{m})\end{array}$ & 0,8 & 0,9 & 0,9 & 0,9 & 3,9 & 4,4 & Homog. \\
\hline 22. Comprimento dos braços abertos $(\mathrm{m})$ & 1,6 & 1,8 & 1,9 & 1,8 & 7,4 & 4,2 & Homog. \\
\hline
\end{tabular}

Onde: $\bar{x}$ = Média; Desv Pad = Desvio Padrão; CV (\%) = Coeficiente de variação em porcentagem, Dist = Distribuição; Heter. = Heterogêneo, Homog = Homogêneo; e IMC = Índice de Massa Corporal (massa corporal.estutura $^{-2}$ ) segundo ANJOS (1992). Fonte: Adaptado de SILVA (2006).

A maioria das variáveis apresentou uma distribuição homogênea, exceto a idade (heterogênea), peso, o IMC e a altura do cotovelo (distribuições médias), fatores que normalmente possuem maior variabilidade. Verificou-se que os trabalhadores possuíam em média 30,7 anos, 1,8 m de altura e 71,3 $\mathrm{kg}$. A grande variação de idade indicou uma distribuição heterogênea. Os trabalhadores mais jovens por terem pouco tempo de experiência e tempo na função, pode ocorrer 
dificuldades na utilização das máquinas. Já os mais velhos, podem ser acometidos por fadigas ou outros desconfortos resultantes de suas limitações físicas e cansaço.

O peso dos trabalhadores apresentou distribuição média $(15,1 \%)$. O ideal é que este esteja em boa qualidade física, segundo ANJO (1992) o Índice de Massa Corporal (IMC) ideal deve ser compreendido entre 18,5 e 25. Em média, os trabalhadores estavam em bom estado físico (IMC de 24). Cuidado especial deve-se ter com os trabalhadores do Percentil (95\%) que apresentaram sobre peso e podem não acompanhar o ritmo de trabalho.

\section{Aplicação das variáveis antropométricas}

Com as medidas antropométricas foi possível dimensionar algumas aplicações no processo de produção de ferramentas, o percentil utilizado e as medidas correspondentes (Tabela 2).

TABELA 2 - Aplicações das medidas antropométricas no processo de produção de ferramentas.

\begin{tabular}{|c|c|c|c|}
\hline Aplicações para produção de ferramentas & $\begin{array}{l}\text { Medidas antropométricas } \\
\text { utilizadas }\end{array}$ & $\begin{array}{l}\text { Percentil } \\
\text { utilizado }\end{array}$ & $\begin{array}{l}\text { Medida } \\
\text { obtida }\end{array}$ \\
\hline $\begin{array}{l}\text { 1. Determinação do ângulo superior e } \\
\text { inferior de visibilidade }\end{array}$ & Altura do nível do olho & $5 \%$ & $1,6 \mathrm{~m}$ \\
\hline $\begin{array}{l}\text { 2. Determinação do limite de visibilidade } \\
\text { horizontal }\end{array}$ & Altura do ombro & $5 \%$ & $1,4 \mathrm{~m}$ \\
\hline $\begin{array}{l}\text { 3. Determinação da altura máxima entre } \\
\text { degraus e obstruções }\end{array}$ & $\begin{array}{l}\text { Altura do joelho na } \\
\text { rótula }\end{array}$ & $5 \%$ & $0,4 \mathrm{~m}$ \\
\hline $\begin{array}{l}\text { 4. Determinação da altura de pedais } \\
\text { para acionamento de máquinas }\end{array}$ & $\begin{array}{l}\text { Metade da altura do } \\
\text { joelho na rótula }\end{array}$ & $5 \%$ & $0,2 \mathrm{~m}$ \\
\hline $\begin{array}{l}\text { 5. Determinação da altura máxima de } \\
\text { comandos a serem acionados frontal } \\
\text { ou lateralmente }\end{array}$ & Altura do tórax & $5 \%$ & $1,2 \mathrm{~m}$ \\
\hline $\begin{array}{l}\text { 6. Determinação da distância vertical } \\
\text { inferior máxima de comandos }\end{array}$ & $\begin{array}{l}\text { Alcance inferior } \\
\text { máximo até a } \\
\text { extremidade do dedo } \\
\text { médio }\end{array}$ & $5 \%$ & $0,6 \mathrm{~m}$ \\
\hline $\begin{array}{l}\text { 7. Determinação da distância de } \\
\text { comandos a serem empunhados } \\
\text { (horizontal) }\end{array}$ & $\begin{array}{l}\text { Alcance frontal da mão } \\
\text { em pega empunhadura }\end{array}$ & $5 \%$ & $0,4 \mathrm{~m}$ \\
\hline $\begin{array}{l}\text { 8. Determinação da largura mínima para } \\
\text { introdução da mão nos cabos das } \\
\text { máquinas e controles do tipo joysticks }\end{array}$ & $\begin{array}{l}\text { Largura da mão no } \\
\text { polegar }\end{array}$ & $95 \%$ & $0,2 \mathrm{~m}$ \\
\hline $\begin{array}{l}\text { 9. Profundidade mínima para introdução } \\
\text { da mão nos cabos das máquinas }\end{array}$ & $\begin{array}{l}\text { Largura da mão } \\
\text { fechada }\end{array}$ & $95 \%$ & $0,1 \mathrm{~m}$ \\
\hline $\begin{array}{l}\text { 10. Determinação da altura da bancada } \\
\text { para trabalhos leves }\end{array}$ & $\begin{array}{l}\text { Altura do cotovelo } \\
\text { subtraído de } 0,1 \mathrm{~m}\end{array}$ & $95 \%$ & $1,1 \mathrm{~m}$ \\
\hline $\begin{array}{l}\text { 11. Determinação da altura da bancada } \\
\text { para trabalhos pesados }\end{array}$ & $\begin{array}{l}\text { Altura do cotovelo } \\
\text { subtraindo } 0,3 \mathrm{~m} \\
\text { Gira-se os antebraços }\end{array}$ & $95 \%$ & $0,9 \mathrm{~m}$ \\
\hline $\begin{array}{l}\text { 12. Determinação da área de alcance } \\
\text { ótimo sobre superfícies horizontais }\end{array}$ & $\begin{array}{l}\text { em torno dos cotovelos } \\
\text { com os braços caídos } \\
\text { normalmente. }\end{array}$ & $5 \%$ & $0,3 \mathrm{~m}^{2}$ \\
\hline $\begin{array}{l}\text { 13. Determinação da área de alcance } \\
\text { máximo sobre superfícies horizontais }\end{array}$ & $\begin{array}{l}\text { Gira-se os braços } \\
\text { estendidos em torno do } \\
\text { ombro }\end{array}$ & $5 \%$ & $1,0 \mathrm{~m}^{2}$ \\
\hline
\end{tabular}


O ângulo superior e inferior de visibilidade e o limite de visibilidade horizontal delimitam o campo de visão dos trabalhadores. Quando as ferramentas, manivelas e comandos encontram-se fora dessa área de visibilidade 0 trabalhador tem dificuldades para visualizar este objeto, necessitando de trocas de posição mais constantes para executar o mesmo trabalho, tendo um desgaste maior para exercer o mesmo trabalho.

É fundamental que os pedais de acionamento das máquinas estejam a altura correta de modo que, seja necessária a elevação da perna dos trabalhadores até a altura recomendada. Assim, evita-se o acionamento acidental de máquinas e reduzse a propensão a queda dos trabalhadores.

A altura da bancada para os trabalhos leves (inserção de cabos e envernizamento) deve ser de 1,1 $\mathrm{m}$ de altura. Bem como a altura das bancadas e consoles para o trabalho pesado, típico da fábrica de produção de ferramentas, deve corresponder a 0,9 m. Para englobar os trabalhadores mais baixos recomenda-se utilizar banquetas de alturas variáveis de até $0,2 \mathrm{~m}$ de altura. As bancadas das máquinas e mesas auxiliares a serem utilizadas, além de possuir altura adequada devem ter dimensões proporcionais ao tipo de atividade que será executada e compleição física dos trabalhadores.

Partindo desse pressuposto as atividades mais frequentes e repetitivas devem localizar-se na zona preferencial ou área de alcance ótimo, para que seus movimentos sejam realizados mais facilmente, apenas com os movimentos dos braços menos gastos energéticos. As tarefas menos frequentes e que exigem menos precisão devem proceder dentro da área de alcance máximo, envolvendo movimentos simultâneos do tronco e ombros. Da mesma forma como FONTANA \& SEIXAS (2007) avaliaram o alcance ótimo e máximo dos comandos das máquinas florestais utilizadas na extração florestal e comparam com as medidas antropométricas dos operadores de forwarder e skidder.

\section{Análise das superfícies horizontais}

Durante o processo de produção de ferramentas eram utilizadas mesas auxiliares para deposição de peças já acabadas para as atividades realizadas no esmeril e têmpera. Para o envernizamento e inserção de cabos, além de promover estas atividades sobre as mesas auxiliares, também serviam de armazenamento para as peças acabadas. A Figura 1 mostra a área e a altura das mesas avaliadas. 


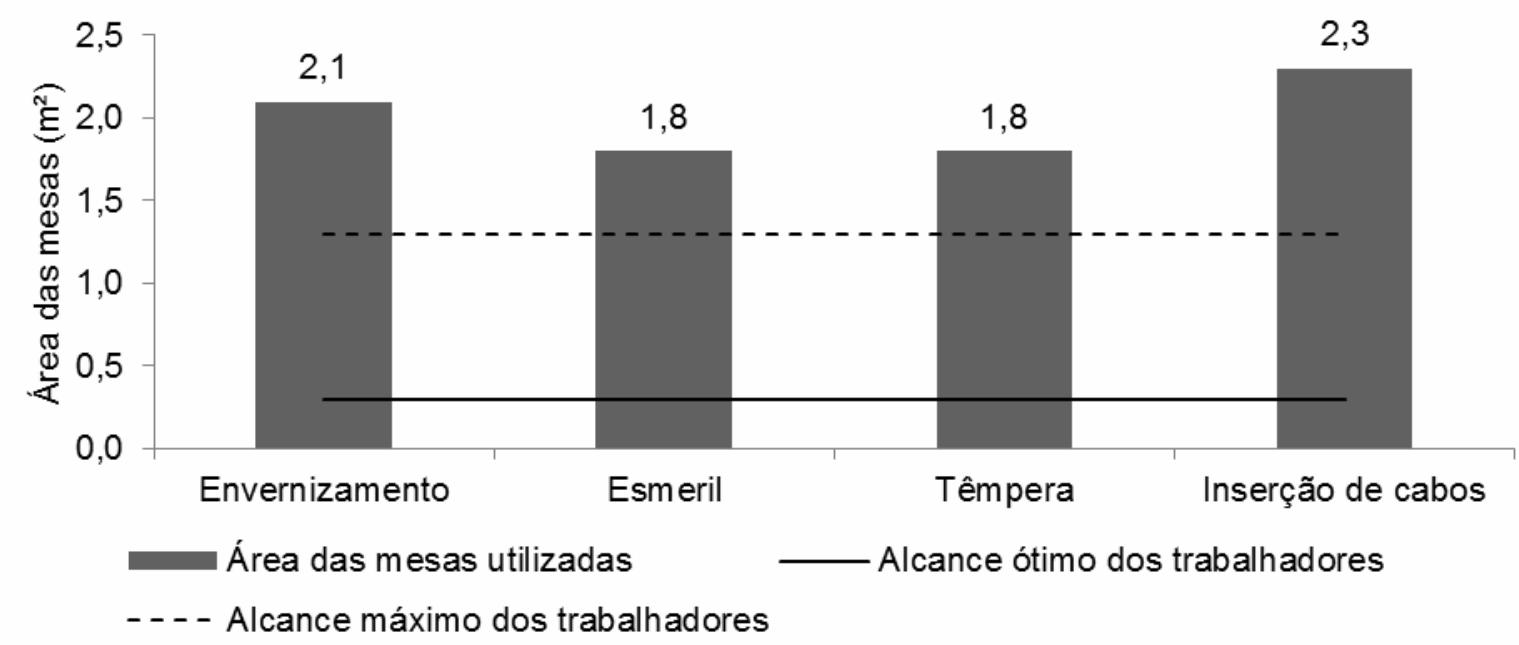

(a)

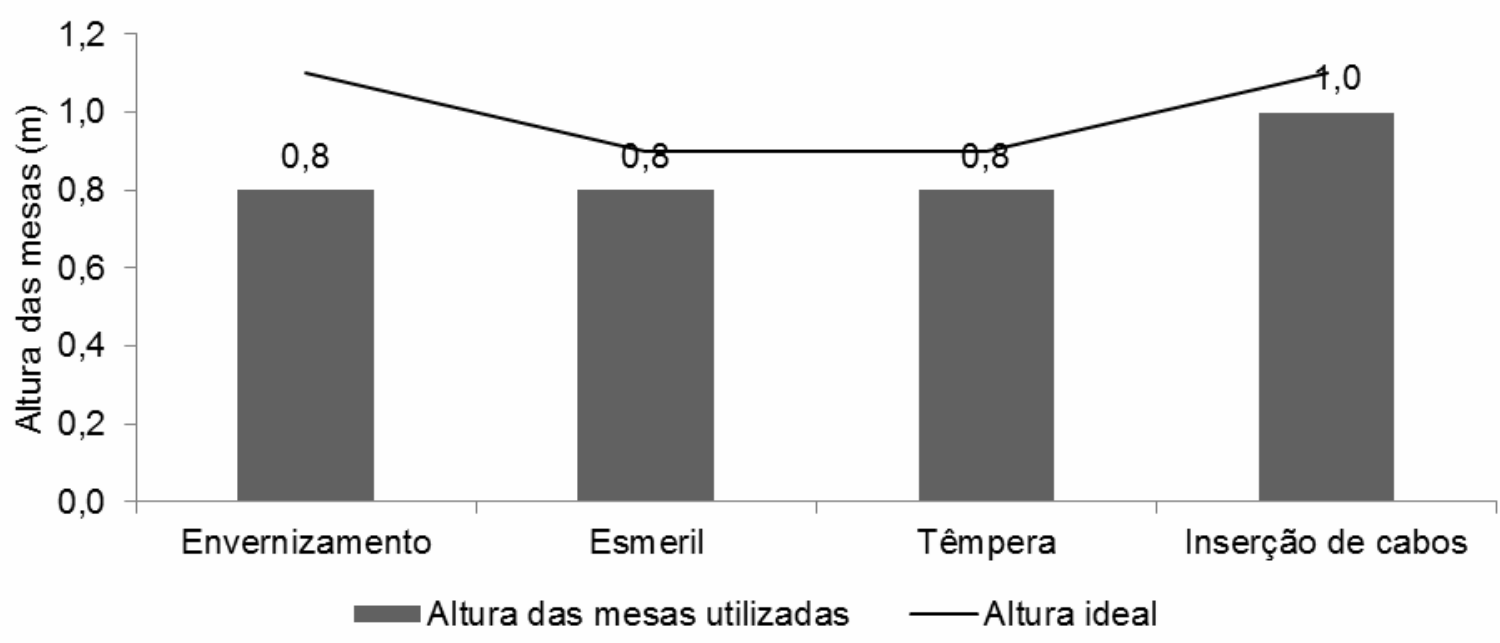

FIGURA 1. Área (a) e altura (b) das mesas avaliadas.

Durante a jornada os trabalhadores passavam muito tempo atuando sobre as superfícies horizontais. Todas as mesas possuíam áreas maiores que o alcance máximo dos trabalhadores, com isso, estes precisavam se movimentar em demasia para percorrer toda a superfície da mesa e concluir suas atividades.

O estudo antropométrico indicou que, para trabalhos leves, as bancadas deveriam se posicionar a uma altura de $1,1 \mathrm{~m}$ e, para trabalhos pesados, 0,9 m. Todas as mesas, mesmo que para trabalhos leves ou pesados, possuíam altura de bancada mais baixas que a ideal.

Conhecendo o perfil antropométrico da população de trabalhadores do pólo moveleiro de Ubá, SILVA et al. (2006) recomendaram as alturas ideais para as bancadas dos postos de trabalho de fabricação de móveis. Para a área de corte, usinagem, lixamento, bancada linha de pintura e embalagem deveriam estar a 1,1 m de altura e todos estes postos estavam abaixo da altura ideal. A Figura 2 mostra a área e a altura da bancada das máquinas avaliadas. 


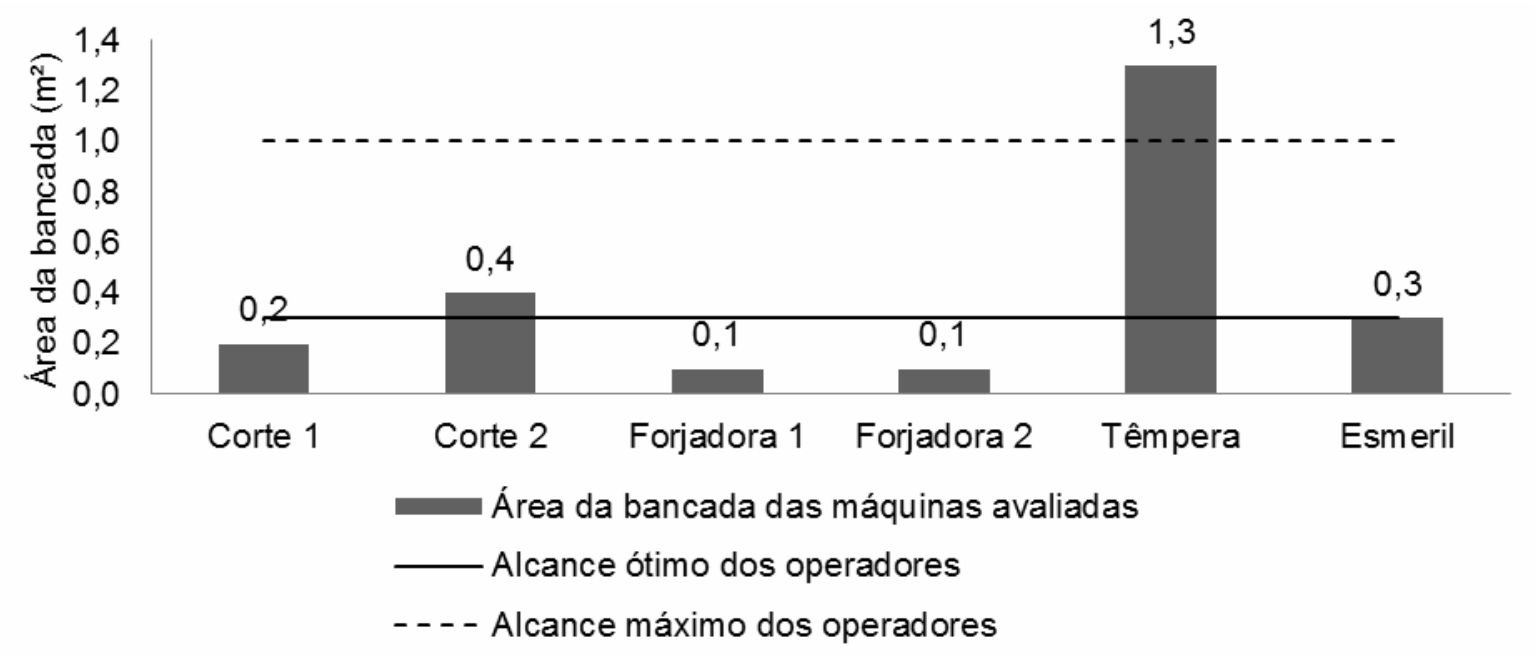

(a)

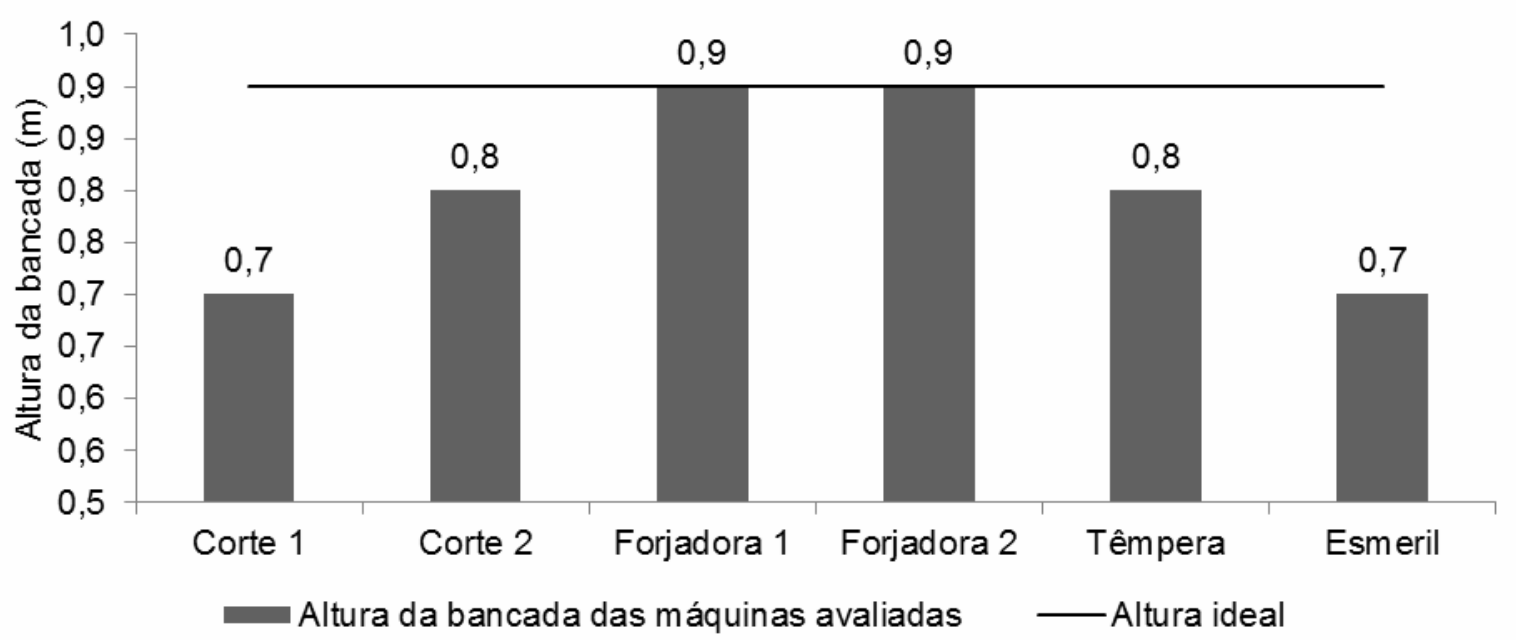

(b)

FIGURA 2. Área (a) e altura das bancadas (b) das máquinas avaliadas.

Todas as máquinas possuíam bancadas com área dentro dos limites ótimos de alcance dos trabalhadores, exceto no corte 2 e na têmpera. Na têmpera, mesmo excedendo o limite máximo de alcance dos trabalhadores, não se utilizava toda a superfície da mesa, pois a atividade se concentrava na região central da mesa, onde o operador mantinha as peças de aço sobre a superfície do fogo para adquirir resistência e durabilidade.

No entanto, além de possuir uma superfície horizontal proporcional ao alcance ótimo dos operadores é preciso que as bancadas estejam a uma altura ideal. As atividades: corte 1 e 2, têmpera e esmeril apresentaram bancadas com altura abaixo da recomendada. Com isso, o trabalhador tinha dificuldades em visualizar suas peças trabalhadas e era forçado a adotar postura irregular que 0 deixava mais fatigado e propenso a erros. As superfícies horizontais das forjadoras apresentaram-se em alturas ideais conforme compleição física de seus trabalhadores. Algumas máquinas possuíam acionamento por pedal, a Figura 3 mostra a área e altura do pedal das máquinas. 


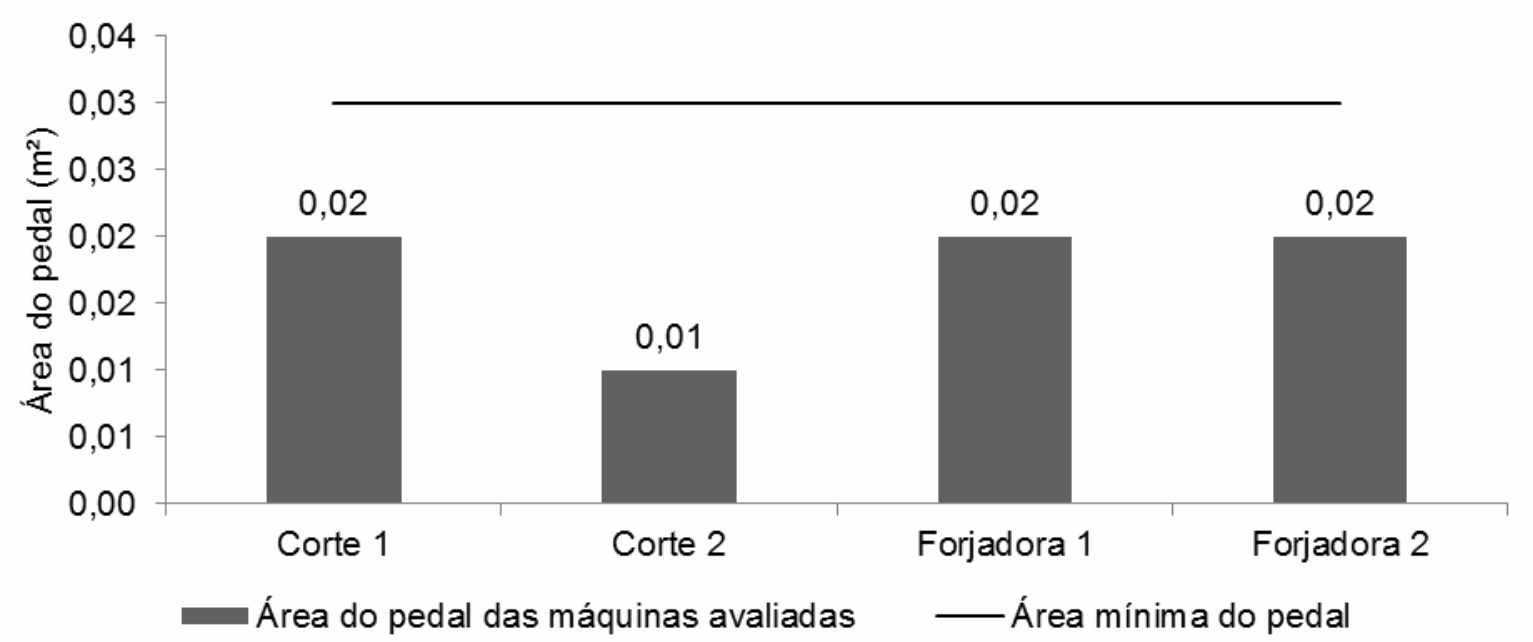

(a)

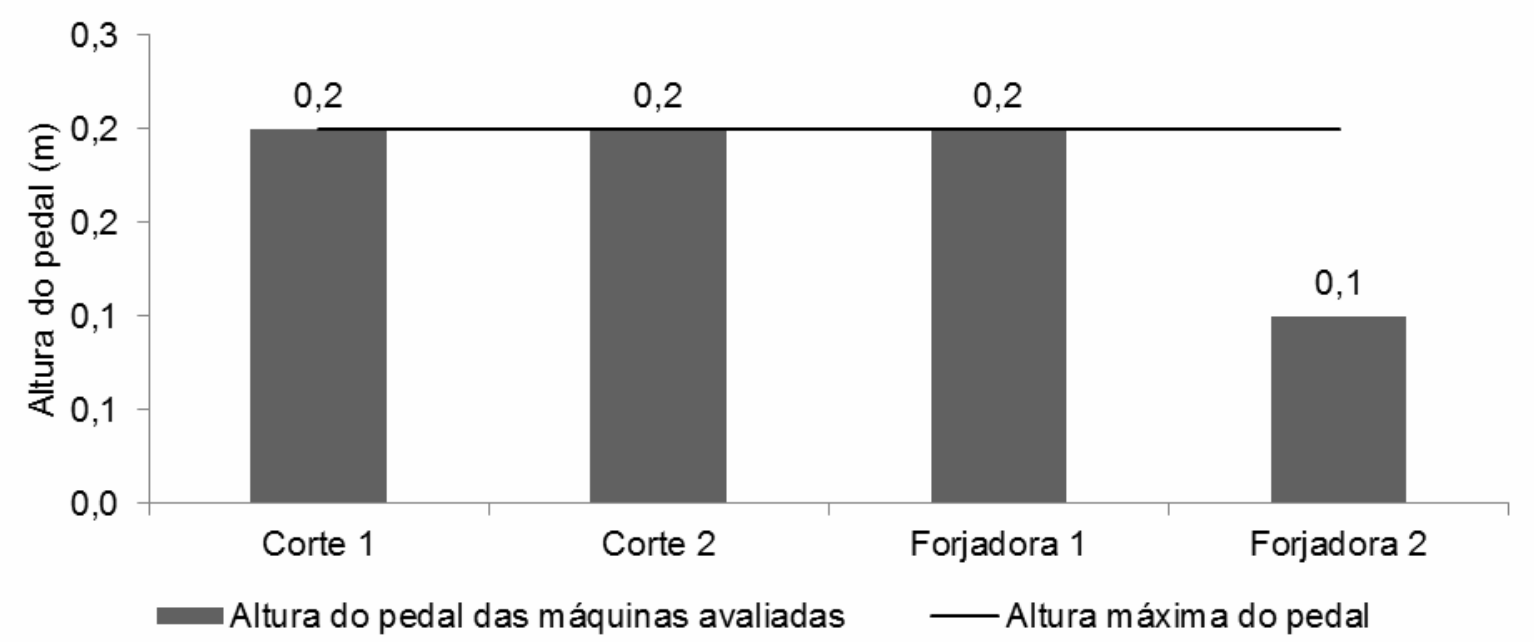

(b)

FIGURA 3. Área e altura do pedal das máquinas avaliadas.

O pedal deveria ter dimensões semelhantes ao tamanho do pé dos operadores. Neste caso, a área mínima dos pedais deveria ter $0,03 \mathrm{~m}^{2}$, de forma que todos os trabalhadores terão facilidade de acionar um pedal.

Todas as atividades que possuíam pedais estavam com suas dimensões menores do que o recomendado. Pedais muito pequenos (como no corte 2) poderiam causar desequilíbrios para que o trabalhador permanecesse na posição de pé sobre uma das pernas e acionasse o pedal com a outra perna.

Os pedais deveriam estar à altura de até $0,2 \mathrm{~m}$. Dessa forma, todas as máquinas estavam dentro do tolerado, exceto a forjadora 2, que possuía dimensões menores e precisa ser redimensionada. Com o pedal de $0,2 \mathrm{~m}$ de altura 0 trabalhador precisava elevar sua perna a uma altura mínima para executar o movimento e, com isso, acionar a máquina sem que fizesse movimentos exagerados e nem acometesse suas articulações em demasia.

\section{Proposição para os EPIs}

A empresa é obrigada a fornecer aos empregados, gratuitamente, EPI adequado ao risco, em perfeito estado de conservação e funcionamento (NR 6, SEGURANÇA E MEDICINA DO TRABALHO, 2012). A Figura 4 ilustra os EPIS ENCICLOPÉDIA BIOSFERA, Centro Científico Conhecer - Goiânia, v.13 n.24; p.1619 
utilizados para produção de ferramentas como protetor auricular de concha, respirador purificador de ar não-motorizado, luvas, calça e camisa.

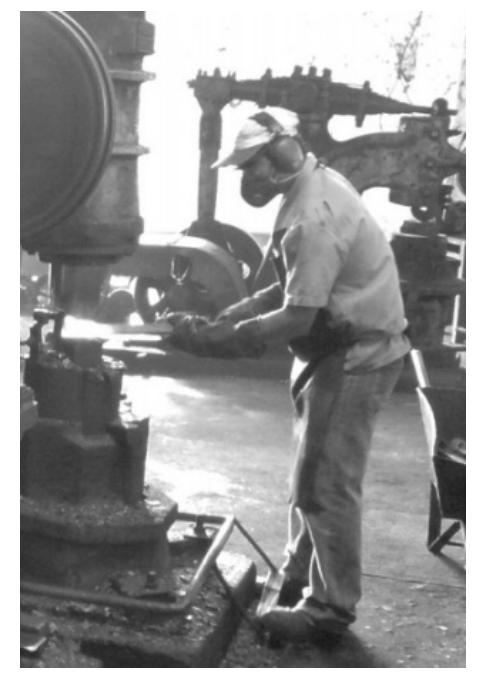

FIGURA 4 - EPIs utilizados pelos trabalhadores.

Por meio das medidas antropométricas foi possível indicar as dimensões dos EPIs recomendadas (Tabela 4).

TABELA 4: Dimensões dos EPIS recomendadas.

\begin{tabular}{llll}
\hline EPIs & $\begin{array}{l}\text { Medidas antropométricas } \\
\text { utilizadas }\end{array}$ & $\begin{array}{l}\text { Percentil } \\
\text { indicado }\end{array}$ & $\begin{array}{l}\text { Medidas } \\
\text { obtidas (m) }\end{array}$ \\
\hline $\begin{array}{l}\text { 1. Protetor auricular de } \\
\text { concha }\end{array}$ & $\begin{array}{l}\text { Estatura menos a altura do } \\
\text { nível do ouvido }\end{array}$ & $95 \%$ & 0,2 \\
$\begin{array}{l}\text { 2. Respirador purificador } \\
\text { de ar não-motorizado }\end{array}$ & $\begin{array}{l}\text { Altura do nível dos olhos } \\
\text { menos a altura do mento } \\
\text { Largura da mão no polegar e }\end{array}$ & $95 \%$ & 0,1 \\
3. Luvas & $\begin{array}{l}\text { comprimento da mão na } \\
\text { extremidade do dedo médio }\end{array}$ & $95 \%$ & $0,2 \times 0$, \\
4. Calça & $\begin{array}{l}\text { Altura entrepernas } \\
\text { Altura dos ombros menos } \\
\text { altura dos punhos }\end{array}$ & 5 e $95 \%$ & 0,7 e 0,8 \\
5. Camisa & $95 \%$ & 0,6 e 0,7 \\
\hline
\end{tabular}

Nota: Todo EPI utilizado deve apresentar o selo CA (Certificado de aprovação) emitido pelo INMETRO.

Os pedidos de compra dos EPIs devem ser proporcionais às características antropométricas dos trabalhadores (dimensões recomendadas). Baseando-se nos percentins 5 e 95\% têm-se um parâmetro para nortear em qual extensão devem ser requisitados os EPIs de tamanhos variados.

GUIMARÃES et al., (2013) analisaram os fatores humanos e condições de trabalho de uma fábrica de produção de ferramentas, sendo considerado quanto aos EPIs utilizados, o avental foi considerado desnecessário e incômodo; a pressão causada pelo protetor auricular de concha foi citada como desconfortável, e o mais torturante dos EPl's era o respirador, pois fazia pressão sobre a região do nariz. Deve-se contabilizar, para cada EPI necessário, o número de trabalhadores que se encontrem abaixo do Percencil 5\% ou acima do Percentil 95\% para a variável ENCICLOPÉDIA BIOSFERA, Centro Científico Conhecer - Goiânia, v.13 n.24; p.1620 2016 
analisada, com o intuito que todos os trabalhadores sejam contemplados com 0 mesmo.

\section{CONCLUSÕES}

Com base nas medidas antropométricas analisadas é preciso readequar as superfícies de trabalho e bancadas das máquinas às alturas correta de trabalho e área de alcance máximo dos trabalhadores

Todas as mesas possuem área maior que o alcance máximo dos trabalhadores e a maioria das atividades apresenta bancada mais baixa que a ideal.

Em relação aos pedais, todas as máquinas possuem altura dentro do aceitável, exceto a forjadora 2, com dimensões menores e que deve ser redimensionada. Em contrapartida, a área dos pedais foram inferiores a área ideal.

Monitorando as medidas antropométricas, além de conhecer o perfil dos trabalhadores é uma base de dados que ajuda no ajuste das dimensões dos EPIs necessários e de algumas variáveis do processo de produção de ferramentas.

\section{REFERÊNCIAS}

ANJOS, L. A. Índice de massa corporal (massa corporal.estatura-2) como indicador do estado nutricional de adultos: revisão de literatura. Revista Saúde Pública. v. 26, n. 6, p. 431-436, 1992.

http://www.scielo.br/scielo.php?script=sci_arttext\&pid=S0034-89101992000600009

FERNANDES, H. C.; BRITO, A. B.; MINETTE, L. J.; LEITE, D. M.; LEITE, E. S. Aplicação de índices ergonômicos na avaliação da cabine de um trator florestal "Feller-Buncher". Scientia Forestalis. Piracicaba, v. 39, n. 90, p. 273-281, 2011.

http://www.ipef.br/publicacoes/scientia/nr90/cap15.pdf

FONTANA, G.; SEIXAS, F. Avaliação ergonômica do posto de trabalho de modelos de "forwarder" e "skidder". Revista Árvore. v. 31, n. 1, 2007.

http://www.scielo.br/scielo.php?script=sci_arttext\&pid=S0100-67622007000100009

GUIMARAES, P. P. Fatores ergonômicos das atividades em uma fábrica de ferramentas. 2011. 93f. Dissertação (Mestrado em Ciências Florestais). Universidade Federal do Espírito Santo. Jerônimo Monteiro.

http://portais4.ufes.br/posgrad/teses/tese_4617_.pdf

GUimARAES, P. P.; FIEDLER, N. C.; CARMO, F. C. A.; ALVES, R. T.; MORAES, F. Aplicações de variáveis antropométricas em postos de trabalho em marcenarias no Sul do Espírito Santo. Floresta. Curitiba, v. 46, n. 1, p. 11-20, 2016.

http://revistas.ufpr.br/floresta/article/view/28831

GUIMARAES, P. P.; FIEDLER, N. C.; CARMO, F. C. A.; OlIVEIRA, J. T. S.; MINETTE, L. J.; MAZIERO, R.; PRADO, L. N. Adequação do layout de uma fábrica de ferramentas florestais baseado em parâmetros ergonômicos. Floresta, v. 43, n. 4, p. 515-524, 2013. http://revistas.ufpr.br/floresta/article/view/28982

GuimaRAES, P. P.; FIEDleR, N. C.; CARMO, F. C. A.; GONÇALVES, S. B. Ergonomia em atividades florestais. Enciclopédia Biosfera, v. 1, n. 1, p. 182-201, 2014. http://www.conhecer.org.br/Agrarian\%20Academy/2014a/ergonomia.pdf 
GUIMARAES, P. P.; FIEDLER, N. C.; LIMA, J. S. S.; LEITE, A. M. P., PELISSARI, A. L. Fatores humanos e condições de trabalho das atividades em uma fábrica de ferramentas. Nativa: Pesquisas Agrárias e Ambientais. v. 1, n.1, p. 49-55, 2013. http://periodicoscientificos.ufmt.br/ojs/index.php/nativa/article/view/1336

IIDA, I. Ergonomia: Projeto e produção, $2^{a}$ ed. Revisada e ampliada. São Paulo: Edgard Blücher; 2005.

LOPES, E. S.; BRITTO, P. C.; LAAT, E. F.; FIEDLER, N. C.; VIEIRA, T. P. Análise antropométrica de trabalhadores em atividades de implantação florestal. Floresta. v. 43, n. 4, p. 525-534, 2013. http://revistas.ufpr.br/floresta/article/view/32612

MINETTE, L. J. Análise de fatores operacionais e ergonômicos na operação de corte florestas com motosserra. 1996. 211f. Tese (Doutorado em Ciência Florestal). Setor de Ciências Agrárias, Universidade Federal de Viçosa, Viçosa.

NORMA REGULAMENTADORA - NR 6 - Equipamentos de Proteção Individual EPI. In: Segurança e Medicina do Trabalho. 70. ed. São Paulo: Atlas, p. 77-82, 2012.

SILVA, K. R.; SOUZA, A. P.; MINETTE, L. J.; COSTA, F. F.; FIALHO, P. B. Avaliação antropométrica de trabalhadores em indústrias do polo moveleiro de Ubá, MG. Revista Árvore, v. 30, n. 4, p. 613-618, 2006.

http://www.scielo.br/scielo.php?script=sci_arttext\&pid=S0100-67622006000400014 